e-ISSN: 1984-4255 $\quad$ ARGUMENTOS

D0I: https://doi.org/10.36517/Argumentos.23.9

\title{
A lucidez dos loucos: Nietzsche e outros
}

\section{The lucidity of the insane: Nietzsche and others}

\author{
Rogerio Parentoni Martins \\ https://orcid.org/0000-0002-5261-7665 - E-mail: rpmartins917@gmail.com
}

Aquele que, como nós, não esteja fora de si mesmo, não pode saber o que é a verdade e onde está a verdade. (NIETZSCHE, 2008, p. 250).

\begin{abstract}
RESUMO
A aceitação das supostas causas da loucura variou na história das culturas. Porém, quaisquer sejam as culturas há dificuldades de se estabelecer claros limites a partir dos quais a loucura pode ser objetivamente identificada. Platão considerava a loucura promovida por meio de um espírito místico que a poucos inspirava. Os pensamentos medieval e renascentista admitiam a loucura como de fundo religioso, moral, médico, divino ou diabólico, boa ou má. No final do século XIX até meados do século XX, a etnopsiquiatria desconsiderava a importância da cultura e da personalidade para entender a loucura, cuja origem seria proveniente da manifestação de uma estrutura patológica básica e universal. De modo semelhante, Freud admitia que a loucura já estivesse presente no inconsciente. A partir dos séculos XVII e XVIII, o cogito cartesiano estabeleceu a supremacia da razão em obter-se conhecimento, o que no século XX motivou a controvérsia Foucault versus Derrida sobre a exclusão da loucura do cogito. No passado, talvez por faltar compreensão adequada, o alienado era excluído do convívio social e tratado por meio de práticas "curativas" muitas vezes violentas. Por isso, muitos tiveram sua doença agravada ou se tornaram abúlicos. Para realizar o diagnóstico da loucura, os profissionais capacitados não devem estabelecer barreiras teóricas entre si e o paciente; este deve ser amplamente ouvido e tratado por equipe interdisciplinar. Finalmente, para Nietzsche a loucura estaria associada ao ímpeto criativo.
\end{abstract}

Palavras-chave: Loucura. Cultura. Cogito. Nietzsche. 


\begin{abstract}
Lunacy has always been reflected upon by Western thinkers. The acceptance of its putative causes has varied across centuries and cultures. In all of them, it has been difficult, above all, to establish boundaries beyond which insanity is definitive. Plato considered insanity to be the manifestation of a mystic spirit that inspired but a few. Medieval and Renaissance thought admitted lunacy's nature to be good or bad, divine or diabolic, religious, moral or health related. Early ethnopsychiatry considered culture and personality unimportant to explain lunacy Similarly, Freud thought that lunacy lives in the subconscious. Starting in the 17th century, the Cartesian paradigm established ${ }^{1}$ reason's supremacy as the mediator of knowledge, which led to Foucault opposition to Derrida's exclusion of lunacy from this paradigm. Lack of adequate understanding of lunacy has led, in the past, to the exclusion of lunatics from social living and the adoption of violent, "curative" therapeutics. In many cases, they have worsened the condition or led to a irreversible breakdown of reasoning ability. Adequate diagnosis and treatment of lunacy require that no theoretical barriers are established between the health professional and the patient; on the contrary, patients issues must be heard and followed by an interdisciplinary team. Finally, according to Nietzsche insanity would be linked to the creative impetus.
\end{abstract}

Keywords: Insanity. Culture. Cogito. Nietzsche.

\title{
Prólogo
}

Informados sobre meu interesse pela filosofia Nietzschiana, três amigos a quem respeito e prezo pela persistência em serem honestos consigo e com os demais, independentemente, surpreenderam-me: "Sabia que Nietzsche é louco?" Soou-me como se decretassem seu perpétuo, posto que definitivo, exílio do mundo das reflexões originais e revolucionárias. Apesar dos amigos evidenciarem a insanidade do filósofo, apenas, o espírito de sua lucidez e coragem não poderá ser apagado sejam quantos séculos se passarem e um único homem livre e questionador restar. O que resta do cadáver do filósofo permanece sepulto, todavia, com ele várias ilusões coletivas que soçobraram sob o peso de suas reflexões.

Agradeço esses amigos pelo mote, incentivo à presente reflexão, não somente sobre o "louco" Nietzsche, mas também a respeito dos significados e empregos do adjetivo como expediente de manutenção do poder médico [(a antipsiquiatria, por exemplo, surgiu com as reflexões de certos psiquiatras e psicanalistas europeus, insatisfeitos com a psiquiatria tradicional exercida pelo poder do médico (MANNONI, 1981, p. 12)], cuja atuação quase sempre resulta em exclusão do convívio social, pessoas com visões de mundo diferentes daquelas de pessoas "normais" de sua cultura. Muitos desses excluídos da convivência social o foram e talvez ainda sejam sem justificativas plausíveis, a não ser o incômodo e constrangimento que suas presenças e lampejos, de sincera lucidez, possam causar às pessoas 'normais', ocultos os verdadeiros propósitos sob frágeis e esquivos argumentos tais como manutenção da ordem pública e bem estar social, esses tacitamente referendados pelo "consenso dos normais".

Conta a piada que um louco alçado no topo do muro do hospício olhava a paisagem circundante, enquanto seu pensamento, pressupostamente ilógico, percorria-lhe o cérebro talvez à procura de lampejos de lucidez. Provavelmente não os encontrando, concentrou-se em ob-

\footnotetext{
${ }^{1}$ Agradecimentos: Aline Pereira dos Santos Amaro Correia revisou o texto. Marcos Soares Barbeitos traduziu o resumo. A Fundação Cearense de Apoio à Pesquisa Científica e Tecnológica (FUNCAP) concedeu-me bolsa de pesquisador visitante.
} 
servar um motorista que, ao tentar trocar um pneu furado, perdera os parafusos que o prendiam à roda. Desolado pela compulsória interrupção de seu trajeto, sentou-se o inconformado condutor sobre o pneu furado, sem que a lucidez lhe trouxesse solução alguma. O louco, talvez ou não penalizado, chamou-lhe a atenção: "por que não retira um parafuso de cada uma das três rodas, cujos pneus permanecem íntegros; prenda-os ao estepe e trafegue em velocidade moderada até a cidade mais próxima, onde poderá adquirir os parafusos que perdeu?". O motorista, atônito, respondeu: "mas você não é louco?". O alienado retorquiu: "louco sou, mas não burro!".

\section{Depoimento pessoal}

Em meados dos anos 70, trabalhava no interior da Bahia investigando ocorrência de "barbeiros", insetos vetores da doença de Chagas, cujo nome popular na região é "bicudo". Parte da investigação consistia em excursões às matas, a fim de tentar encontrar ninhos de aves e tocas de mamíferos, nas quais várias espécies de "bicudo" poderiam potencialmente ser encontradas. Para o êxito dessas incursões necessitava a companhia de alguém que conhecesse as matas da região. Sugeriram-me contatar um homem de um vilarejo adstrito à Barreiras, minha cidade hospedeira. Com as sugestões vieram advertências: "cuidado, o homem é doido!". Sinceramente, isso não me importava muito, até mesmo porque não se tinha notícia de agressão que tivesse perpetrado a outrem.

Durante as caminhadas, meu acompanhante, homem de língua "destravada", proferia bravatas, por exemplo, que não tinha medo de nada e andava com cobras nos bolsos. De uma feita, andava ele à minha frente quando vi uma inofensiva cobra-cipó em um galho ao alcance de minha mão. Peguei-a, o chamei e a lancei em direção a ele: "ponha no bolso!" Assustado, recuou e disse: "Rogério, tu é doido!" Reconheceu-me como semelhante e, a partir dali, dedicou-me bastante respeito.

O "mateiro" era um homem forte, bem-disposto, capaz de atravessar a nado, sem se cansar, os 100 metros que separavam as margens do Rio Grande, que ladeava a cidade Barreiras, enquanto eu me empoleirava no galho de um ingazeiro tombado sobre o rio. Naquela época, próximo ao rio, havia uma base do Projeto Rondon, Campus avançado da UFMG, na qual me hospedava. O bravateiro logo se enturmou com os alunos que lá chegavam, principalmente as alunas, que lhe davam bastante atenção. Isso lhe despertou desejo sexual. Porém, como percebi-lhe as intenções, dissuadi-lhe de tentar abordar as estagiárias rondonistas com intenções sexuais. Ouviu-me, mas com o passar dos dias o desejo cresceu de tal forma, que tentou estuprar uma jovem de seu vilarejo. Soube do ocorrido, comunicado pelo delegado da cidade que o trancafiou.

Na delegacia, o delegado, cujo rosto lembrava o de Napoleão Bonaparte, assentiu-me que o "elemento" era de alta periculosidade para sociedade, por isso não poderia soltá-lo. 0 mateiro, no entanto, pediu-me que propusesse ao delegado que lhe desse a oportunidade para que durante o dia continuasse a trabalhar comigo e à noite eu o traria para dormir na prisão. $\mathrm{O}$ delegado recusou-se sob a mesma alegação anterior.

Durante os poucos dias que continuei o trabalho, diariamente o visitava, até meu retorno a Belo Horizonte. Quinze dias passados de meu retorno, informaram-me que o'napoleônico' delegado resolvera encaminhá-lo ao Hospital Raul Soares, conhecido sanatório alienista em Belo Horizonte. Algumas vezes fui visitá-lo e, ao contrário do que esperava, o encontrei bem-disposto. Perguntei-lhe sobre o que o médico Ihe havia indagado. Respondeu-me que o doutor lhe perguntou se ouvia vozes dentro da cabeça, o que ele assentiu. Perguntei-lhe também por que ele nunca havia me falado a respeito. Justificou, logicamente, que jamais lhe 
havia perguntado. Durante a internação, tornou-se líder dos demais internos, dos quais dizia serem muito loucos. Organizava-os como em um "coral" e os conduzia diariamente a cantar: "tá todo mundo louco, tá todo mundo louco"; menos ele...

Após a conclusão do tratamento, encarregaram-me que levasse de volta ao vilarejo um homem derrotado e apático como resultado da medicação que lhe fora administrada. Assim mesmo, durante a viagem, animava-se um pouco diante a possibilidade de rever a tia e sobrinhos.

Visitei-o duas vezes na casa da tia, onde morava. Nessas ocasiões, consternado, presenciei dois ataques epilépticos que amedrontaram seus familiares, pois os associavam à possessão demoníaca, uma associação comumente feita na idade média, principalmente a partir da queda do império romano (KEMP, 1985, p. 1).

Antes de retornar a Belo Horizonte, generoso médico, com quem eu tinha amizade, graciosamente assumiu-Ihe o tratamento. Nunca mais retornei a Barreiras, onde conheci um homem de físico saudável, bem-disposto, lúcido na maioria das vezes, e deixei um epilético derrotado talvez para o resto de sua vida.

\section{O estado de ânimo lunático}

Duas questões assomam-se: o que é ser louco e como é um louco? A primeira não deve ser muito fácil responder, exatamente pelo fato do discurso dos loucos dissociados não seguirem a lógica corriqueira e, por isso, dificultar a interpretação pelos "normais" que se dispuserem a ouvi-lo. Além da própria discriminação leiga preconceituosa, certos profissionais podem, durante a anamnese, interpor entre si e o suposto alienado barreiras de interceptação do discurso. Alguns deles talvez até prefiram calar a voz dos alienados ministrando-lhes drogas que os torna abúlicos. A segunda pergunta não deve ser tão difícil responder por meio de observações comparativas e reflexões. Neste caso julgo necessário que a "voz" dos alienados seja ouvida em sua completude, devido não apenas às dificuldades de articulações lógicas da linguagem, causadas pela sua dissociação cognitiva, mas também a seus possíveis lampejos de lucidez.

Outras questões decorrem das formuladas no parágrafo anterior: por que se encarceram certos loucos e não certos 'normais' que cometam desatinos, dissimulam, trapaceiam e prejudicam a outrem, apesar de serem considerados por muitos "espertos" por que os braços da justiça não os alcançaram? Por que até o louco não agressivo pode incomodar os que supostamente não o são? Por que os loucos ficam agressivos? Quem de fato são os 'normais'? Quem de fato são os loucos? Por que as sociedades em geral toleram certos tipos de loucos? Por que seriam, talvez, exemplos perfeitos para que possam exercer sua hipocrisia ou abrandar o complexo de culpa cristão? Abriria a porta de sua compreensão para alguém julgado louco pelo senso comum, ou o evitaria?

Confesso-me incapaz de responder todas essas questões, que devem ser de interesse para aquelas pessoas que se dizem humanizadas, mesmo que essa suposta humanização possa, às vezes, inesperadamente, se romper pelo afloramento do animal compulsoriamente abrigado em cada um, que consegue sobrepor-se à razão e intensamente manifestar comportamentos instintivos. Enfim, se a razão dos'normais' é salvo-conduto que os afasta da loucura, por que certas pessoas antes consideradas 'normais' também se tornam sujeitas à fratura da razão?

\section{A fratura da razão}

Viver sem propósito algum, se possível, deve ser insuportável; viver com propósitos restritos, embora suportável, poderá alienar de variadas formas. Todos, talvez, carregamos a se- 
mente da loucura potencialmente capaz de se desenvolver em insanidade ou se manter "dormente" por meio de conduta cautelosa durante a vida, até a inevitável chegada da demência senil ou Alzheimer ("preço" pago por vários aqueles dos que muito vivem) consuma os últimos anos de nossas vidas. Uma das questões na filosofia sobre o surgimento ou não da alienação é sobre como devemos evitá-la.

Como é bem conhecido, as bases do epicurismo são ataraxia (paz de espírito) e aponia (ausência de dor) para atingir eudamonia (felicidade). $O$ estoicismo pregava a virtude como o único bem e meio de alcançar a felicidade por meio da negação dos sentimentos externos; evitando o prazer, que é inimigo dos sábios; por ser uma razão "natural" que governa o universo e pela valorização da indiferença. Tanto a paz de espírito como a indiferença poderiam e podem funcionar como barreiras contra a perda do juízo. Por outro lado, cabe crítica ao uso do adjetivo "natural", mais ainda quando se refere à "razão natural": seu uso é de rara infelicidade, visto que não há definição clara do termo, embora na raiz refira-se ao que procede da natureza. Porém, o que é natureza? O homem é natural? A biologia afirma que sim, as religiões em geral afirmam que não, que foi criado por um ser supremo. $E$ os demais seres vivos, pressupostamente criados também por um ser supremo, são naturais? O verbete, sobretudo, é usado como se a natureza fosse algo fixo, invariável e inevitável no tempo e espaço, o que proporciona entrave à discussão aprofundada sobre quaisquer temas que o inclua. Ser natural garante ao objeto assim designado legitimidade sem necessidade de explicação sobre seu significado, como se aquém e além dessa "natureza" nada mais houvesse. Os considerados insanos seriam naturais?

Tendo como paradigma a concepção essencialista, "invariabilidade natural", a etnopsiquiatria, desde o final do século XIX, estudava a loucura como se independesse da cultura e da personalidade do indivíduo: "o essencial do adoecer psíquico, estaria dado pelo processo patogênico de fundo; a cultura e a personalidade do doente apenas preencheriam uma estrutura patológica básica, em si imutável, dando-lhe aparências variáveis." (DALGALARRONDO, 1997, p. 9).

Em tempos mais recentes, alguns pesquisadores passaram a defender a tese de que as diferenças culturais, não seriam epifenômenos apenas de uma manifestação psíquica universal (DALGALARRONDO, 1997, p. 10). Desse modo, a psiquiatria passaria a dar atenção a esses epifenômenos, não apenas na caracterização da doença, mas como possíveis causas da insanidade.

Caso a loucura puder, todavia, ser considerada como extravasamento incontrolável de certas emoções, aqueles que conseguem contê-las, agindo de forma indiferente ou com ceticismo, poderiam se imunizar, talvez, quanto às consequências que esse extravasamento poderia lhes causar?

Conter todas as emoções ou tornar-se indiferente pode levar a uma vida insossa; constantemente emocionar-se por quaisquer motivos pode levar talvez à loucura. Essas são condições extremas de um contínuo de respostas comportamentais. O influente apotegma cartesiano--existir é pensar-- supervalorizou o papel da razão; contribuiu para a desconfiança de muitos cientistas e pensadores sobre o papel que as emoções desempenham nas performances existencial e criativa. Rotular um indivíduo de emocional, seria uma forma de dizer que esse indivíduo comumente expressa a emoção à frente da razão. Por isso, em debates que envolvam opiniões conflitantes, aquele que extravasa suas emoções, ao tentar defender sua opinião, tende a ser visto como não confiável ou mesmo desprovido de argumentos.

Em sua análise multifacetada sobre as várias interpretações sobre a emoção na qual contrasta as reflexões de vários filósofos sobre o papel das emoções como sentimentos irracionais, atributos animais (boa parte dos filósofos racionalistas como Descartes), Solomon (2011, p. 39- 
105) omite a relação entre emoção e loucura, embora a loucura seja algumas vezes um estado emotivo extremo que pode atingir níveis de manifestações fortes e incontroláveis. No entanto, quanto à manifestação de fortes emoções, vários filósofos ocidentais e orientais convergiram a um ponto comum a respeito de seus efeitos indesejáveis sobre o bem-estar (SOLOMON, 2011, p. 39-105). Talvez, a loucura tenha sido omitida dessa "categoria" que abrange efeitos indesejáveis sobre o bem-estar, por sempre ter sido considerada uma categoria sui generis. Por outro lado: "No ocidente individualista, o distúrbio mental, se ligeiro, é relativamente "legitimo"... Porque acreditamos que temos direito à felicidade, acreditamos também que temos direito de reclamar quando estamos mal, um direito de alívio (PORTER, 1990, p. 17).

Opor-se radicalmente a emoção à razão, como extremos irreconciliáveis, obscurece os papéis que ambas desempenham no comportamento individual. Imagine um indivíduo totalmente racional que desejar ir a um restaurante e, para isso, questione sobre a qualidade da comida, sobre a distância dos restaurantes à sua casa; sobre a violência potencial a que estaria exposto no percurso de sua casa ao restaurante e deste à sua casa; compare os preços dos mesmos pratos servidos em outros restaurantes, e etc. São tantos os questionamentos, que se ele não adotar uma atitude emocional, dificilmente decidirá sair de casa para ir ao restaurante. Se esse mesmo indivíduo replicar esse comportamento para lidar com as diversas atividades cotidianas, poderá se tornar, talvez, neurótico ou quem sabe psicótico.

Raciocínio semelhante, mas oposto, é válido para outro indivíduo que age inteiramente de forma emocional, que saia por impulso, sem o mínimo planejamento que o oriente a seu objetivo. Se o vago objetivo for ir a um restaurante, correrá o risco de que, ao chegar, esse esteja fechado ou que simplesmente não o localize. É possível também argumentar sobre a situação de um hipotético matemático que conseguira solucionar um problema ao qual dedicara vários dias de trabalho. Com grande possibilidade, ao encontrar a solução, deveria se emocionar. Caso não se emocione, talvez seu desejo de encontrar soluções para outros problemas, os quais Ihe consumam dias de reflexão, diminua. O que o desejo é senão a expressão da expectativa da emoção?

Além de paz de espírito e indiferença, haveria algum outro meio a impedir a fratura, muitas vezes, irreparável da razão e, simultaneamente, viver também emoções? Os artistas e gênios considerados insanos talvez possam responder. Porém, mais indicado, possivelmente, para tentar compreender-lhes a loucura, seria ouvi-los quando se referem às suas crises demenciais e surtos criativos. Até porque as narrativas dos profissionais que diagnosticam tais estados alterados de consciência são extremamente técnicas. A fim de obter maior realismo e consistência sobre essas manifestações de alienação, os significados da fala dos acometidos poderão trazer compreensão mais próxima da realidade em que se encontram, quando comparadas às interpretações eventuais proferidas pelos profissionais do comportamento e pelo 'consenso dos normais'.

Escritos autobiográficos de gênios que enlouqueceram podem ser bons exemplos de sua loucura e lucidez quando, conscientemente, identificam-nas durante a ocorrência de episódios de alienação: "Os escritos dos loucos podem ser lidos não só como sintoma de doenças e síndromes, mas também como comunicação coerente em si mesma." (PORTER, 1990, p. 8).

Esse tipo de auto-avaliação talvez seja com alguma frequência ignorado pelos médicos, psicólogos e psicanalistas como auxiliar de diagnóstico, apesar de que, potencialmente, possam ser importantes para auxiliar o entendimento da loucura. Em geral, esses profissionais, armados de conhecimento teórico, devem se sentir mais seguros quando encontram em teorias pressupostamente consolidadas, suporte para orientar o diagnóstico e o tratamento. Essa segurança poderá, todavia, fazer com que os referidos profissionais tentem somente "encaixar" os sintomas 
nas concepções teóricas mais aceitas, a exemplo do já comentado neste texto sobre a história da etnopsiquiatria. Ignorar outras peculiaridades da fala do paciente, não previstas pelas teorias, poderá ser importante para o diagnóstico e tratamento adequados. Pode ser que, algumas vezes, ouçam pacientes que lhes foram encaminhados, já com hipótese de "anomalia" comportamental qualquer. Nestes casos, o simples fato de serem encaminhados com essa expectativa poderá influenciar alguns desses profissionais quanto à formulação correta do diagnóstico da doença. Ademais, "em louco não se pode confiar", estabelecem as autoridades constituídas e legitimadas capazes de decidir sobre a exclusão do diagnosticado da convivência social.

Os loucos criativos têm sua dose de razão em desconfiar dos médicos e dos tratamentos propostos, como foi o caso de Virginia Wolf. A escritora desconfiava da doutrina vigente à sua época de que pessoas criativas eram neuróticas. Temia que o tratamento psiquiátrico subtraísse sua criatividade. Escreveu a uma interlocutora descrevendo um momento de 'insanidade' criativa: "meu cérebro explodiu numa chuva de fogos de artifício." (PORTER, 1990, p. 80).

À medida que o idealismo platônico e a inversão idealista de Aristóteles (PRADO JR., 2012, p. 42) se difundiram, tornando-se bases dos pensamentos filosófico e científico ocidental, predominou entre os homens 'normais', mais intensamente a partir do século XVII, o paradigma do comando das atitudes por meio da razão: "os filósofos gregos sujeitaram energicamente a natureza, a sociedade, a consciência à razão. Eles queriam domar a anarquia, estabelecer a ordem, impor a autodisciplina. A racionalidade tornou-se definitivamente a mais nobre faculdade do homem." (PORTER, 1990, p. 19).

Com o cogito cartesiano, a supremacia da razão passou a ser como uma espécie de imperativo categórico Kantiano. Os racionalistas, profissionais ou leigos, se encarregavam de estigmatizar os que praticavam atitudes consideradas ignorantes, tolas ou desprovidas de utilidade, pois meramente seriam ilusões e sonhos (PORTER, 1990, p. 23). Certos cientistas, cujos sonhos se mostraram úteis para suas descobertas, não sofreram esse tipo de discriminação: seus sonhos foram encarados como auxiliares legítimos de descobertas científicas e incorporados à história da ciência. O químico orgânico alemão August Kekulé, por exemplo, concluiu sobre a estrutura "hexocarbônica" do anel de benzeno, baseado em sonho no qual visualizou uma serpente que retorcia o próprio corpo. Fazia-o de tal modo que a cabeça tocava a cauda descrevendo uma figura urobórica. Sugestivamente, o símbolo uróboro (gr., oura=cauda; boro=devorar) está ligado à alquimia, termo originário do árabe "a química". Einstein revelou um sonho o qual diz tê-lo feito meditar sobre a velocidade da luz: descia uma montanha coberta de neve em um trenó cuja velocidade era próxima à da luz. Não houve contemporâneos que acusassem esses cientistas de insanidade, excêntricos talvez, apesar do sonho, além de não encontrar lugar no cogito cartesiano, era por Descartes também considerado: "mais inverossímil que a loucura" (DERRIDA \& FOUCAULT, 2001, p. 77).

Derrida e Foucault confrontaram suas opiniões contrárias sobre a exclusão da loucura do cogito cartesiano. O primeiro opinou que Foucault não lera Descartes corretamente; para Derrida, o cogito cartesiano não excluía a insanidade do processo de meditação: "O louco não se engana sempre e em tudo; ele não se engana o suficiente, ele nunca é louco o suficiente" (DERRIDA \& FOUCAULT, 2001, p. 43). “Para Descartes, a loucura é pensada somente como um caso, entre outros, e não o mais grave de erro sensível." (DERRIDA \& FOUCAULT, 2001, p. 44).

Foucault inicia sua réplica observando que Derrida pretendeu entender o sentido de seu "História da Loucura" a partir das três páginas nas quais analisa o cogito cartesiano sob a perspectiva da loucura (DERRIDA \& FOUCAULT, 2001, p. 69). Mas, o que ele teria argumentado foi a suposição de que: 
[...] a filosofia se apresenta como crítica universal de todo o saber, sem a análise real do conteúdo e das formas das formas do saber; como injunção moral que só se desperta com sua própria luz; como perpétua reprodução dela própria, em um comentário infinito que não mantém nenhuma relação com a exterioridade. (DERRIDA \& FOUCAULT, 2001, p. 74).

O que estava em questão no debate entre Foucault e Derrida era a própria legitimidade da filosofia fechada em si própria, sobretudo, imune à crítica sobre sua hegemonia sobre qualquer tipo de saber. A loucura foi apenas um motivo para que os dois pensadores refletissem sobre o"poder" da filosofia sobre o conhecimento. O objeto da filosofia, todavia, não é o conhecimento em si, mas o conhecimento sobre o conhecimento (PRADO JR., 2012, p. 14-15).

Se o debate de fato trouxe alguma luz reveladora sobre o domínio da filosofia, permito-me duvidar. Certo foi o episódio ter abalado a amizade entre o mestre Foucault e o discípulo Derrida, embora permanecesse o respeito intelectual e admiração que ambos reciprocamente nutriam. Todavia, tenha ou não Foucault razão sobre a inclusão da loucura no pensamento racionalista, seu História da Loucura é de considerável interesse para quem se interessa sobre tema, nos séculos XVII e XVIII, que marcaram a tentativa bem-sucedida da hegemonia da racionalidade sobre a emoção. De forma mais específica e diferente do que aconteceu a várias outras concepções que fundamentaram o pensamento, os possíveis significados da loucura foram também motivos de reflexão de filósofos gregos (PORTER, 1990, p. 19).

\section{O conceito de loucura em Nietzsche}

Há várias especulações sobre as causas orgânicas que originaram a loucura que acometeu o filósofo, especialmente no último ano de sua vida. No entanto, essas permanecem especulativas, especialmente porque seu corpo não foi submetido a exumação. São pelos menos seis possibilidades hipotéticas elencadas:

1. Paralysis progressive (General paralysis of the insane) 2. Bipolar affective disorder followed by vascular dementia 3. Hereditary form of frontotemporal dementia 4. Brain tumor 5. Cerebral autosomal dominant arteriopathy with subcortical infarcts and leukoencephalopathy (CADASIL) 6. Mitochondrial encephalomyopathy with lactic acidosis and stroke-like episodes (MELAS) syndrome. (TÉNYI 2012, p. 420).

Porém, independentemente das dúvidas sobre os diagnósticos de sua enfermidade, aqui mencionadas en passant apenas, interessa-me discutir qual o conceito o filósofo teria sobre a loucura e se o auto-aplicava.

Uma concepção central de Nietzsche sobre a loucura é o papel que desempenha na criatividade: "[...] quase em todas as partes é a loucura que aplaina o caminho para a ideia nova, a que rompe barreiras de um costume, de uma superstição venerada. Compreendeis por que tem sido necessária a ajuda da loucura?" (NIETZSCHE 2008, p. 22). Se para ele atingir a loucura seria a única maneira de chegar-se ao verdadeiro conhecimento ou ao conhecimento original, será que mesmo insano, ele nutria certo conhecimento de seu estado mórbido? Talvez poderíamos encontrar indícios, desse auto-conhecimento, caso existam, em sua última obra autobiográfica Ecce Homo (NIETZSCHE, 2003). Nessa obra, escrita como quer seu tradutor para o português, "no limiar- inclusive temporal- entre a razão e a loucura" (BACKES 2003, p. 10). Mas será que tal limiar seria identificado tão claramente como um raio de luz em densa escuridão? Mais ainda porque o tradutor viu a insânia do filósofo aumentar a cada página à medida que o relato de Ecce Homo trafegava (BACKES, 2003, nota de rodapé 16, p. 31). Se não for apenas força de expressão do tradutor, talvez seja uma tarefa não trivial rastrear detalhadamente, página por 
página, esse aumento do estado insano, até mesmo porque o ímpeto vigoroso da narrativa de Nietzsche poderá induzir a erro interpretativo. Ele próprio reconhece esse ímpeto comparando-se a um guerreiro: "A minha maneira de ser é guerreira. Atacar faz parte de meus instintos." (NIETZSCHE, 2003, p. 37).

Já no início de seu relato em Ecce Homo, Nietzsche demonstrava reconhecer seu estado mórbido (antes da insânia se manifestar esse estado já era claro), inclusive fraqueza psicológica e dores constantes, como determinantes da clareza que via em uma de suas obras anteriores:

A clareza e serenidade totais, até mesmo a exuberância de espírito que a obra [neste caso se refere à Aurora, Nietzsche (2008)], que a obra mencionada reflete, pode ser entendida não apenas devido à fraqueza psicológica mais profunda, mas inclusive por um excesso de sensações de dor. (NIETZSCHE, 2003, p. 23).

Reconhecia o filósofo que sua longa enfermidade seria responsável pela libertação de ressentimentos (NIETZSCHE, 2003, p. 35), o que o alçaria de certa forma acima dos homens comuns. Outro comportamento revelado pelo filósofo, que de certa forma o alçaria acima dos homens comuns é"o asco ao ser humano, à "gentalha" sempre foi meu maior perigo"(NIETZSCHE, 2003, p. 40) e a solidão para ele era um estado de "pureza" onde ele poderia sentir genuinamente a liberdade de ser. Apesar de ser especulativo, pode ser plausível que esse sentimento de intolerância radical ao convívio social já denotasse uma certa alteração mental que atingiu o ápice em seu último ano de existência. Além da solidão, a ênfase do filósofo sobre o papel da enfermidade na profundidade de seu pensamento abissal é ressaltada em vários momentos como o exemplo, " Quando eu estava quase chegado ao fim, porque estava no fim, eu passei a refletir sobre essa irracionalidade fundamental de minha vida - o "idealismo". Só a enfermidade me trouxe à razão." (NIETZSCHE, 2003, p. 50). De certa forma, essa 'lucidez insana' revelada ao final de sua vida parece ter dado ao filósofo o ímpeto necessário para concluir a apreciação de si mesmo como homem e como pensador. O homem e o pensador se amalgamam quando Nietzsche admite a sim mesmo ser o destinatário de "tarefas grandiosas" (NIETZSCHE, 2003, p. 65). Esse amálgama, essa indistinção entre o homem e as vicissitudes que experimenta, talvez denotem que a razão estivesse se escoando, neste auto-relato no final de sua existência. De modo semelhante ao admitir-se como o próprio significado de "grandeza" pairando soberano por sobre todos os mortais pode ser tentar "agarrar-se" ao fio de lucidez que ainda persiste em sua conturbada mente: "Se eu quiser medir-me por aquilo que posso... então por certo tenho, mais do que qualquer um dentre os mortais, o direito de reivindicar para mim a palavra grandeza" (NIETZSCHE, 2003, p. 66). Em seguida esse sintoma de superioridade se extravasa quando o filósofo admite:

Quem me viu durante os setenta dias de outono, em que, sem interrupções, eu produzi apenas coisas de primeira categoria - coisas que nenhum ser humano é capaz de fazer depois de mim, imitando...ou de fazer antes de mim fingindo- com a responsabilidade tal em relação aos milênios que se seguirão a mim. (NIETZSCHE, 2003, p. 67).

Segue o filósofo, (aqui uso seu próprio termo, "transvalorizando-se") quando afirma: "eu sou o antiasno par excellence e por isso um monstro histórico-universal - eu sou em grego e não apenas em grego o Anticristo" (NIETZSCHE, 2003, p. 74), o que também mostra sua obsessão aguda contra o cristianismo. Comentando sobre sua "arte de estilo", Nietzsche, reconhece uma multiplicidade de estados internos (inclusive o gérmen da insanidade?): "Comunicar uma tensão interna de páthos (dentre outros significados, sofrimento, doença), através de sinais inclusive da velocidade de sinais - esse é o sentido de todo estilo."(NIETZSCHE, 2003, p. 77). Ele também se vê como um "psicólogo sem igual" (NIETZSCHE, 2003, p. 78) aquele 
que compreenderia como ninguém as causas da doença (cristianismo, idealismo) da qual padece a alma dos homens. Como antídoto, o filósofo propõe os ensinamentos de seu Zaratrusta: "[...] jamais alguém achará uma expressão tão grandiosa para o acontecimento Zaratrusta - 0 ato de uma purificação colossal e de consagração da humanidade." (NIETZSCHE, 2003, p. 88). A grandiloquência, que em seu relato reiteradamente aparece, o faz considerar-se acima dos mortais, talvez almejando um lugar ao lado dos deuses gregos, pode mais uma vez ser observada: "Aquilo que eu hoje sou, onde eu hoje estou - em uma altura na qual eu não falo mais através de palavras, mas sim através de raios." (NIETZSCHE, 2003, p. 94). O isolamento tão característico de sua personalidade autocentrada, a quase total incapacidade de relacionar-se socialmente e o profundo desprezo que nutria contra os alemães seus contemporâneos, ele identificava quase como uma doença: "Num lugar escondido nas profundezas da floresta Boêmia, em Klingenbrunn, eu carreguei comigo minha melancolia e meu profundo desprezo aos alemães como se fossem quase uma doença." (NIETZSCHE, 2003, p. 99). E por que esse estado de espírito não poderia ser uma semente de insanidade que, dormente, esperasse o tempo "certo" para brotar? Continua o pensador ser o detentor de uma tarefa das mais nobres: preparar a humanidade para a suprema tomada de consciência, como se somente ele fosse capaz de redimir a humanidade de certa "cegueira existencial"; mais um indício de insanidade, nesse caso messiânica, como outros, talvez insanos também, assim se comportaram: "Minha tarefa de preparar para a humanidade um momento de suprema tomada de consciência." (NIETZSCHE, 2003, p. 105). Mais além, ainda há um Nietzsche auto-revestido de uma grande responsabilidade, mais uma vez como se fosse o titã Atlas, incumbido de uma tarefa inacessível aos mortais: "Pois eu trago o destino da humanidade sobre os ombros." (NIETZSCHE, 2003, p. 143).

Embora, outros indícios, como os aqui indicados da leitura de "Ecce Homo", possam certamente ainda ser encontrados. Eu creio que aqueles expostos são mais que suficientes para caracterizar o caráter insano do filósofo, principalmente sua grandiloquência e caráter messiânico, além das mudanças de estado de humor que poderiam hipoteticamente caracterizá-lo como bipolar. Enfim, advirto que essa é apenas uma interpretação do suposto estado insano desse intenso e profícuo pensador.

\section{Brevíssima incursão na história da loucura}

Distintamente de Foucault (1978) que analisou o fenômeno loucura em uma perspectiva institucional, nesta secção a exemplo do que abordei sobre Nietzsche na secção anterior, interessa-me focalizar a insanidade de uma perspectiva individual (mas obviamente não desvinculada do contexto social, embora pairam dúvidas sobre a natureza da insanidade tanto como do comportamento humano em geral sobre o que determina o comportamento humano, a natureza, cultura ou um amálgama de ambos), destacando alguns protagonistas famosos cujas vidas foram dedicadas à busca incansável da originalidade principalmente nas artes e filosofia, como se verá mais abaixo.

Também de uma perspectiva individual, Platão considerava as situações de insanidade promovidas por um espírito místico (PORTER, 1999, p. 81). Freud, por sua vez, atribuía àqueles estados como manifestações do inconsciente:

À pergunta: que é a loucura? Freud respondeu mostrando que não era preciso opor a loucura à normalidade. $\mathrm{O}$ que se descobre na loucura está de certa maneira já no inconsciente de cada um e os loucos simplesmente sucumbiram numa luta que é a mesma para todos e que todos temos de conduzir sem interrupção. (MANNONI, 1981, p. 37). 
De certo modo, a concepção freudiana de que a loucura já está no inconsciente de cada um, é uma forma de universalização da loucura, o que guarda semelhança à concepção paradigmática dosetnopsiquiatras do final do séculoXIXatémeados do séculoXX (DALGALARRONDO, 1997, p. 31).

Entre Platão e Freud, poderia comentar as interpretações sobre a origem da loucura, seja de fundo místico ou de fundo orgânico, que constituíram a variedade de interpretações sobre o estado de insanidade. Preferi, todavia, como destaquei acima, ater-me à própria palavra daqueles loucos que escreveram sobre suas próprias manifestações de insanidade, tendo mostrado alguma lucidez em seus relatos. Minha opção é pautada pelo maior interesse que tenho sobre os indivíduos, que sobre o que as instituições tenham a declarar sobre seus estados de insanidade. Por isso, segui o caminho que Porter (1990) originalmente trilhou. Selecionei, no entanto, apenas alguns dos autobiografados mencionados por ele, de acordo com minha empatia pelas suas realizações intelectuais e artísticas e pelo impacto que suas ideias (inclusive sobre a própria demência) ou performances originais possam ter causado sobre as configurações das manifestações culturais das épocas em que viveram.

Porter (1990) analisou autobiografias de certos gênios das artes e filosofia, que podem dar pistas sobre como esses gênios, considerados loucos, reconheciam-se nesses estados cognitivos diferenciados. Suas vozes dissonantes interferiam na possibilidade de êxito dos projetos de dominação, por meio de suas ações desmistificadoras de ideologias leigas ou sacras, como o fez em Genealogia da Moral, Nietzsche (2007). Como os propugnadores desse projeto de dominação são hegemônicos sobre os meios de comunicação, o que corriqueiramente faziam, e fazem ainda, é desqualificar essas incômodas vozes, rotulando seus emissores insanos. É conveniente ressaltar que, para a formação da opinião pública, a loucura tem um peso considerável como um fator de seu desinteresse por essas pessoas alienadas, e, mais ainda, destina amplo apoio a seu encarceramento. Não me interessa explorar se os estados de alienação dessas personalidades foram causados por externalidades (e.g., místicas) ou interioridades (e.g., inconsciente). Por outro lado, as menções a Platão e Freud servirão de marcos históricos apenas, extremos de um amplo elenco de pensadores que meditaram sobre fenômeno loucura através dos séculos, mas cujas reflexões serão aqui omitidas.

Os pensamentos medieval e renascentista viam a loucura como de fundo religioso, moral, médico, divino ou diabólico, boa ou má (PORTER, 1990, p. 21). Neste último caso predominava o estabelecimento desses conceitos, conforme emitido por homens nobres e religiosos que se denominavam bons e diziam serem maus os pobres e ignorantes (NIETZSCHE, 2007 p. 27). Já a divinização ou satanização dos loucos ainda é comum em algumas crenças religiosas, como, por exemplo, umbandismo, espiritismo e evangélicos pentecostais, que reúnem pessoas crédulas, facilmente influenciáveis, que afirmam estabelecer contatos com divindades. Há esquizofrênicos em momentos de dissociação que podem admitir comunicar-se com Deus, Cristo e santos, quando não acreditarem que sejam os próprios. Pode ser que na imaginação dos alterados de consciência passarem-se por tais entidades lhes deem a sensação de importância, não reconhecida pela indiferença dos "normais".

Embora, episodicamente, o discurso de Nijinsky e outros gênios terem ocasionalmente sido de extrema lucidez, foram internados por períodos variáveis; no caso de Nijinsky quatro anos (PORTER, 1990, p. 98). Os denominados "loucos mansos", quando não internados em alas psiquiátricas menos vigiadas, são tolerados e, até mesmo em certos casos de cidades pequenas e médias, considerados pelos "normais" "nossos loucos". Nesse caso são tratados como mascotes ou motivo de divertimento. Seriam tolerados para mostrar o sentimento cristão dos "normais" e o quanto seriam caridosos? Por outro lado, aqueles loucos em grandes metrópoles pe- 
rambulantes pelas ruas são "respeitosamente" evitados. Esse modelo de consideração e convivência com os loucos procede da idade média, época em que os lunáticos eram cuidados por membros da família. Os desamparados eram sujeitos à vigilância da comunidade de pequenas aldeias da época, ou como acontece atualmente, também deixados a perambular (PORTER, 1998, p. 22). No entanto, é mais comum hoje instituições assistencialistas religiosas, hospitais psiquiátricos mantidos pelo Estado, ou da iniciativa privada, receberem e cuidarem de certos lunáticos.

Ao final do século XIX, a escola psiquiátrica que defendia ser a loucura uma espécie de degeneração física, enquadrava como doentes mentais certos gênios filosóficos, literários, cientistas, compositores e artísticos, por exemplo, Nietzsche, o poeta maldito (Rimbaud), cientistas (Newton), compositores (Schumann) e escritores (Perceval). O australiano John Perceval foi um exemplo de lucidez sobre seu estado de consciência, quando reconhecia que seu discurso de louco era de fato estranho, mas que as autoridades que lidaram com ele optaram por se fazerem de surdas, posto que entendia o seu discurso como não truncado e de fácil compreensão (PORTER, 1990, p. 49). Perceval admitia que a doença mental era a perda da razão, ou que esta teria sido possuída pela imaginação. Por exemplo, supostamente, ele acreditava na realidade do demônio e as tentações que exercia como contribuintes de suas confusões mentais: "Para Perceval, a doença mental era antes de tudo e principalmente a perda da razão, ou a razão possuída pela imaginação." (PORTER, 1990, p. 223). Provavelmente, devido aos períodos de lucidez, nos quais conseguia refletir sobre sua própria loucura, o caso do pintor seja paradigmático quanto a se ignorar do discurso e a consequente decretação do estado de insanidade, o que pode ter atingido muitos outros, gênios ou não, que não eram dementes, diferentes apenas.

Relembro parte apenas de meu depoimento pessoal acima sobre o diálogo com meu ajudante de campo. Ele, que não era gênio algum, tinha momentos de cristalina lucidez: havia-me sugerido convencer o delegado que o permitisse sair da cela durante o dia para trabaIhar comigo, que estaria encarregado de trazê-lo ao final do trabalho para a cadeia. Apesar de o delegado ter negado meu pedido, julguei que a solicitação era bem razoável. Além de lógica, ele me respeitava o bastante para não descumprir o compromisso. Esse comportamento de meu ajudante de campo, provavelmente, indica períodos de lucidez nos quais as proposições lógicas realistas predominam no discurso do alienado em questões de interesse imediato. A fratura da razão, em grande número de casos, não seja talvez tão irreversível, a não ser que o confinamento e a administração de drogas seja o caminho mais fácil do que empregar um esforço interdisciplinar para tentar recuperá-los e possibilitar sua reintegração social. No entanto sempre serão estigmatizados pelos "normais".

Há quem considere a grandiloquência como um sinal de alienação, e não como possível entusiasmo por ter vislumbrado soluções para problemas de naturezas diversas, julgando-a manifestação exagerada e ultrapassante do limite da "normalidade". A grandiloquência foi uma das manifestações de Nietzsche no período que antecedeu a completa fratura da razão e quando escrevia seus últimos livros (Crepúsculo do Deuses, O Anti-Cristo e Ecce Homo). Porém, Porter (1990, p. 179) afirma que a manifestação de grandiloquência de Nietzsche não foi de loucura. O que é questionável. Por outro lado, seria possível definir precisamente qual seria o limite a partir do qual a fratura da razão tornaria incongruentes quaisquer tipos de discursos, além de caracterizar um total desinteresse do alienado sobre si próprio e pelas coisas do mundo? Porter acha que a partir do outono de 1888 ocorreu seu "desligamento" completo, época em a megalomania atingiu seu ápice (PORTER, 1998, p. 174).

Antes que chegasse à completa fratura da razão, que o tornou incomunicável (aqui também poderiam estar hipoteticamente envolvidas causas meramente orgânicas), mos- 
trou-se um pensador, lúcido, consistente e aguerrido que defendia suas idéias revolucionárias com ímpeto e vigor. Propugnava por um tipo de viver em que os homens expressassem sua potência de viver. Viveu fiel às suas convicções, esse estilo de viver, que materializaram em seu próprio modo de existir.

A arqueologia histórica da loucura (FOUCAUT, 2014) é uma obra indispensável para se tentar compreender principalmente o papel das mudanças culturais e instituições nos séculos XVII e XVIII, expoentes do predomínio da racionalidade como condutora do comportamento. Foram séculos marcados por um intenso intervencionismo, referendado pelos psiquiatras, apoiados pelo poder público. Os resultados desses tipos de intervencionismos, muitas vezes, deixaram desamparado o alienista que não dispunha de recursos financeiros próprios, familiares ou de amizades para promover assistência domiciliar. Algumas instituições públicas albergantes de alienados comumente se tornavam e provavelmente ainda hoje há as que são verdadeiros depósitos de pessoas diagnosticadas como incapazes de conviver socialmente devido à sua insanidade.

Embora Porter (1990) e Foucault (2014) abordem a loucura sob o contexto social, o que é inevitável, obviamente, o primeiro ao estudar os textos autobiográficos nos quais certos gênios e artistas, escrevem sobre suas próprias sensações de insanidade, dedica-se mais especificamente à elaboração, como o próprio título do livro indica, de Uma História Social da Loucura. Apesar de serem histórias individuais, com suas peculiaridades e contextos específicos, é possível perceber que há algo em comum na insânia entre os diferentes personagens abordados. Entre elas grandiloquência, deambulações constantes, ausência de autoreferência.

Os insanos albergados em instituições públicas em alguma medida desprovidas de recursos humanos bem treinados e infraestrutura, eram internados compulsoriamente, via de regra, de forma desumana. A maioria era transformada em criaturas abúlicas ou incomunicáveis também como resultado de administração de drogas ou outros recursos como choques elétricos e lobotomia frontal. Essas condições "assistenciais" precárias resultam no encarceramento dos alienados em si próprios, incapazes de mínima iniciativa para cuidar de si. Enquanto Porter (1990) deixa entrever principalmente a loucura sob a perspectiva individual, Foucault (2014), como já mencionado, aborda a loucura sob o ponto de vista das instituições criadas especificamente para lidar com os alienados. Nessa perspectiva é explícito em alinhavar a tessitura urdida pelos poderes da Igreja e outras autoridades para justificar a interdição compulsória avalizada pelos médicos de loucos.

A mensagem que os loucos emitem aos 'normais' não é a de: "ajudem-me"; é sobre a solidão dos homens, que espreita e ronda cada um e dela procuramos escapar por meio de atitudes muitas vezes dissimuladas e um viver "cosmético". Nessa solidão é onde Nietzsche, encarcerado, se perdeu nos poucos últimos anos de sua vida, inclusive durante o tempo que escreveu Ecce Homo, no qual enfatiza o que julgava de mais relevante na maioria de sua obra. Como um homem louco pode sintetizar a maior parte de sua obra de uma forma lógica? Onde em meio à loucura encontrava lucidez para escrever? Ninguém talvez possa afirmar, todavia, que a solidão crônica seja causa da loucura, mas quem sabe não seria um dos motivos do início de uma jornada sem retorno ou de retornos eventuais até a fratura definitiva da razão?

\section{Referências}

BACKES, M. Breve introdução à importância de Nietzsche. p. 14, In: NIETZSCHE, F. Ecce Homo. São Paulo: Editora L\&PM, 2003. 
DALGALARRONDO, P. Civilização e Loucura. Uma introdução à história da etnopsiquiatria. São Paulo: Editora Lemos, 1997.

DERRIDA, J; FOUCAULT, M. Três Tempos da História da Loucura. Rio de Janeiro: Relume Dumará, 2001.

FOUCAULT, M. História da Loucura. São Paulo: Ed. Perspectiva, 2014.

KEMP, S. Modern mith and medieval madness: views of mental illness in the european midle ages and renaissance. New Zealand Journal of Psychology, v.14, n. 1, p. 1-8, 1985.

MANNONI, M. O. O Psiquiatra, Seu "louco" e a Psicanálise. Rio de Janeiro: Zahar Editor, 1971.

NIETZSCHE, F. W. Ecce Homo. São Paulo: Editora L\&PM, 2003.

NIETZSCHE, F. W. A Genealogia da Moral. 2. ed. São Paulo: Editora Escala, 2007.

NIETZSCHE, F. W. Aurora: reflexões sobre os preconceitos morais. São Paulo: Ed. Vozes, 2008.

PRADO Jr., C. O Que é Filosofia. São Paulo: Editora Brasilense, 2012.

PORTER, R. Uma História Social da Loucura. Rio de Janeiro: Zahar Editor, 1990.

SOLOMON, R. C. O Prazer da Filosofia. Rio de Janeiro: Civilização Brasileira, 2011.

TÉNYI, T. The madness of Dionysus: six hypotheses on the illness of Nietzsche. Psychiatry Hungarian, v. 27, n. 6, p. 420-425, 2012.

\section{Sobre o autor}

\section{Rogerio Parentoni Martins}

Graduado e licenciado em História Natural pela Universidade Federal de Minas Gerais (1974), mestrado em Ecologia pela Universidade Estadual de Campinas (1980) e doutorado em Ecologia pela Universidade Estadual de Campinas (1991). Pós-doutorado no Departamento de Zoologia da Universidade da Florida, Gainesville. Aposentado pela UFMG onde coordenou por 5 anos o programa de pós graduação em Ecologia, Conservação e Manejo de Vida Silvestre. Atualmente é pesquisador-visitante I CNPq/Funcap no Departamento de Biologia da Universidade Federal do Ceará, Fortaleza. Foi coordenador de área da CAPES e CNPq. Tem experiência na área de Ecologia e Comportamento, com ênfase em Ecologia Teórica, atuando principalmente nos seguintes temas: filosofia da ecologia, interdisciplinaridade, biodiversidade, educação, desenvolvimento sustentável e conservação. 